\title{
Avasküler nekrozda medikal tedavi
}

\author{
Medical treatment in avascular necrosis
}

\author{
Mehmet Akif Çaçan ${ }^{1}$, Yılmaz Mertsoy² \\ ${ }^{1}$ İstanbul Medipol Üniversitesi Tıp Fakültesi, Ortopedi ve Travmatoloji Anabilim Dalı, İstanbul \\ ${ }^{2}$ Gazi Yaşargil Eğitim ve Araştırma Hastanesi, Ortopedi ve Travmatoloji Kliniği, Diyarbakır
}

\begin{abstract}
Avasküler nekroz tedavisinde günümüzde cerrahi ve cerrahi olmayan yöntemler mevcuttur. Tedavi seçenekleri birçok faktöre bağlıdır ve standart bir tedavi şekli yoktur. Her hasta için kişiye özel tedavi uygulanmalıdır. Tedavide etkili faktörler: Hastanın yaşı, semptomların şiddeti (ağrı/rahatsızlık seviyesi), nekrozun yeri ve kapsamı, komorbiditeler ve eklem yüzeyi çöküşünün meydana gelip gelmediğidir. Cerrahi olmayan yöntemler daha çok hastalığın erken evrelerinde kullanılmaktadır. Medikal tedavide kullanılan ilaçlar nonsteroid anti-enflamatuvarlar, vazodilatörler (ilioprost), statinler, bisfosfonatlar ve antikoagülanlardır. Bu ajanların kullanım yeri avasküler nekrozun etiyolojisine ve evresine göre değişkenlik gösterir. Literatürde sözkonusu ilaçların avasküler nekrozun tedavisinde etkili olduğunu gösteren çalışmalar olduğu gibi yararsız olduğunu dile getiren çalışmalar da mevcuttur.
\end{abstract}

Anahtar sözcülkler: avasküler nekroz; medikal tedavi; ilaç tedavisi; konservatif tedavi
In the treatment of avascular necrosis, there are currently available methods as surgical and non-surgical. There is no standard form of treatment and treatment options depend on many factors. Individual treatment should be applied for each patient. Effective factors in treatment are the patient's age, severity of symptoms (level of pain/discomfort), location and extent of necrosis, comorbidities and whether joint surface collapse occurs. Non-surgical methods are mostly used in the early stages of the disease. Medicines used in medical treatment are nonsteroidal anti-inflammatories, vasodilators (ilioprost), statins, biphosphonates and anticoagulants. The use of these agents varies according to the etiology and stage of avascular necrosis. In the literature, there are studies demonstrate that these drugs are effective in the treatment of avascular necrosis, as well as studies stating that they are useless.

Key words: avascular necrosis; medical therapy; medication; conservative treatment
A vasküler nekrozun tedavisinde cerrahi ve cerrahi olmayan yöntemler mevcuttur. Hangi tedavinin kullanılacağı hastalığın etiyolojisine ve evresine göre belirlenir. Literatürde daha çok femur başı ile ilişkili avasküler nekrozun tedavisi tartışılmıştır. Biz de bu makalede daha çok femur başı avasküler nekrozunun medikal tedavisini ele aldık. Avasküler nekroz, ilerleme ve/veya çökme açısından belirgin bir varyasyon gösterir. Küçük asemptomatik lezyonlar kendiliğinden düzelebilmesine rağmen, çoğu lezyon ilerleme gösterir ve tedavi gerektirir. ${ }^{[1]}$ Femur başı avasküler nekrozu tedavi edilmezse 2-3 yıl içinde subkondral kırıklara yol açabilir. Tedaviler hem cerrahi hem de cerrahi dışı seçenekleri içerir. Konservatif tedaviler konusunda bir görüş yoktur. Tedavi kararı lezyonların evrelemesine göre yapılır, ancak esas olarak çökme varlığına veya yokluğuna dayanmalıdır. Genellikle cerrahi dışı tedaviler ve/veya kor (core) dekompresyon asemptomatik ve semptomatik küçükorta büyüklükteki çökme öncesi lezyonlarda etkilidir. Konservatif yaklaşım, çeşitli ameliyat dışı tedavileri kapsar. Bunlar; fizik tedavi, kısıtlı ağırlık taşıma, alkolün bırakılması, steroid tedavisinin kesilmesi, ağıı kontrol ilaçları ve hedefli farmakolojik tedaviyi içerebilir. ${ }^{[2]}$ Avasküler nekrozda (AVN'de) her ne kadar cerrahi öncesi konservatif tedavi uygulansa da bunun etkinliği tartışmalıdır. Mont ve ark. tarafından AVN'li toplam 819 kalça ile yapılan 21 çalışma gözden geçirilmiş ve cerrahi olmayan yöntemle tedavi edilen hastalarda sadece \%23'lük bir başarı oranı gösterilmiştir. ${ }^{[3]}$

- Illetişim adresi: Dr. Mehmet Akif Çaçan, Göztepe, Metin Sk. No: 4, 34214 Bağcılar, İstanbul Tel: 0536 - 3005410 e-posta: mehmetakifcacan@hotmail.com

- Geliş tarihi: 6 Eylül $2020 \quad$ Kabul tarihi: 29 Eylül 2020 
Avasküler nekrozun medikal tedavisinde bazı ilaçlar kullanılabilir. Bunlar;

1. Nonsteroid anti-enflamatuvarlar (NSAi)

2. Vazodilatörler (ilioprost)

3. Lipid düşürücü ilaçlar (Statinler)

4. Bisfosfonatlar

5. Antikoagülanlar (Enoksaparin, asetik salisilik asit)

\section{Nonsteroid Anti-enflamatuvarlar}

AVN'de en önemli klinik bulgu ağrıdır. NSAi ilaçlar AVN erken safhalarında tedaviden çok ağrının giderilmesinde kullanılır. Semptomları azaltabilir fakat kemiğin beslenmesinin restorasyonu ve avasküler nekrozun gerilemesini sağlamaz. ${ }^{[2]}$

\section{Vazodilatörler (ilioprost)}

Prostasiklin analoğu olan ilioprost vazoaktif prostaglandin (PGI2) analoğudur. Şiddetli periferik vasküler hastalık (Raynaud fenomeni), diyabetik anjiyopati, pulmoner hipertansiyon ve organ nakli sonrası tedavi dâhil olmak üzere çeşitli alanlarda kullanılmıştır. Avasküler nekrozda vazodilatasyon yapıp intraosseöz basıncı düşürerek kan akışının artması amaçlanır. Beş gün süreyle damar yolu ile uygulamanın kısıtlı serilerde ödem ve ağrıyı azalttığı rapor edilmiştir. ${ }^{[4]}$ Meizer ve ark., ilioprost ile tedavi edilen farklı eklem bölgelerinde ağrılı kemik iliği ödemi olan 104 hastayı analiz etmiştir. Dört aylık kısa süreli takip ile hastaların \%73'ünde ağıı seviyelerinde azalma hastaların \%65'inde kemik iliği ödem büyüklüğünde azalma veya tamamen normalleşme bildirmişlerdir. ${ }^{\left[{ }^{[}\right]}$Tim Claßen ve ark., ilioprostun uzun dönem (50 ay) etkinliğini değerlendirdikleri çalışmalarında farklı eklem, etiyoloji ve ciddiyette 136 osteonekrozu olan toplam 108 hasta değerlendirmiş ve hastaların çoğunda $(\% 74,8)$, ilioprost tedavisinden sonra subjektif şikâyetlerde belirgin bir iyileşme ve VAS (Vizuel Analog Skala) ağrı skorlarında azalma göstermişlerdir. Cerrahiye gidiş: evre 2'de \%20, evre 3'de \%71 ve evre 4'te \%100 olarak tespit edilmiştir. ${ }^{[6]}$

\section{Lipid Düşürücü illaçlar (Statinler)}

Kortikosteroid kaynaklı AVN için olası bir etiyoloji kemik iliğinde yağ birikmesidir. Bu da intraosseöz basıncın artmasına ve kan akışında azalmaya neden olur. Kolesterol sentezini bloke ederek lipit seviyelerini düşüren statinler potansiyel olarak bu etkileri önleyebilir. Lovastatin ile tedavi edilen steroid kaynaklı AVN'ye sahip bir tavuk modelinde adipogenez ve kemik ölümünün azaldığı izlenmiş ancak geriye dönük insan çalışmalarında bunu destekleyecek yeterli veri yoktur. Yapılan bir kadavra çalışmasında 3000'den fazla böbrek nakli incelenmiş ve statin kullanımı ile AVN riski azalması arasında istatistiksel olarak anlamlı bir ilişki bulunmamıştır. ${ }^{[7]}$ Pritchett tarafından yapılan bir çalışmada, hem yüksek doz steroid hem de statini beraber alan hastalar incelenmiştir. Ortalama 7,5 yıllık takipten sonra sadece üç hastada (\%1) AVN tespit edilmiş olup bu insidans genellikle yüksek doz steroid alan hastalar için bildirilen \%3 ila \%20 insidanstan çok daha azdır. Buna göre statinler, steroid tedavisi gereken hastalıklarda steroidlerle beraber alındığında osteonekroz gelişmesine karşı koruma sağlayabilir. ${ }^{[8]}$

\section{Bisfosfonatlar}

Femur başı osteonekrozunda en çok çalışma yapılmış olan ilaç bisfosfonatlardır. Osteoklast aktivitesini azaltan bisfosfonatlar teorik olarak nekrotik bölgede oluşan artmış kemik döngüsünü inhibe ederek erken femur başı AVN'li hastalarda femur başı çökmesini önleyebilir. ${ }^{[9]}$

İnsanlarda haftada 35-70 mg alendronat uygulamasının, evre 1 ve 2 kalçalarda hiç tedavi etmemeye göre daha iyi olduğu gösterilmiş. Agarwalla ve ark., AVN'li 395 kalçayı 3 yıl boyunca alendronat ile tedavi etmişlerdir. Hiçbir tedavinin yapılmadığı diğer çalışmaların bulgularına kıyasla, klinik fonksiyonda iyileşme, çökme oranında azalma ve total kalça protezi gereksiniminde azalma olduğu gösterilmiştir. ${ }^{[10]}$ İnsan çalışması sonuçlarının kesin olmadığını bildiren çalışmalar da mevcuttur. Lee ve ark.'nın yaptığı ileriye dönük, randomize, çok merkezli çalışmada toplam 110 hasta değerlendirilmiş ve 55 hastaya 2 yıl boyunca zolendronat verilmiş. Sonrasında orta ve geniş nekrotik alanı olan femur başı Steinberg evre I veya II osteonekrozu için zoledronat, femur başı çökmesini önlemediği gibi total kalça artroplastisi ihtiyacını da azaltmamıştır (kanıt düzeyi: terapötik düzey I). ${ }^{111]}$ Yuan ve ark., beş randomize klinik çalışmayı içeren meta-analizlerinde, bisfosfonatlarla tedavi edilen femur başı AVN hastalarında istatistiksel olarak anlamlı bir iyileşme saptamadıklarını bildirmişlerdir. ${ }^{[12]}$ Li ve ark.'nın hem hayvan hem de insan çalışmalarını içeren 2018 yılındaki meta-analizinde hayvan modeli sonuçlarında iyileşme olmasına rağmen, insanlar için iyileşme gösterilememiştir. ${ }^{[13]}$ Bisfosfonatların atipik proksimal femur kırıkları ve çenenin osteonekrozu gibi olumsuz etkileri olabileceği düşünüldüğünde ${ }^{[12]}$, erken evre femur başı $A V N$ 'de bu tedaviyi rutin olarak tavsiye etmeden önce daha kesin araştırmalara ihtiyaç vardır. 


\section{Antikoagülanlar}

Avasküler nekroz patofizyolojisi için öngörülen mekanizmalardan biri damar içi oklüzyondur. Buna göre antikoagülanlar ve vazodilatörler teorik olarak hastalığın ilerlemesini geciktirebilir, hatta tersine çevirebilir. Ancak bunu destekleyici veriler sınırlıdır. ${ }^{[14]}$ Glueck ve ark.'nın yaptığı antikoagülan enoksaparin ile tedavi edilen ve koagülopati ile ilişkili femur başı AVN'li 30 kalçayla ilgili ileriye dönük bir çalışmada hastaların \%53'ünün Ficat-Arlet evre 1 ve 2'yi geçmediği gösterilmiştir. Bu çalışmada hastalar $60 \mathrm{mg} /$ gün enoksaparin ile 3 ay tedavi edilmiştir. Primer osteonekrozu olan hastaların sadece \%12'sinde femur başı çökmesi izlenmiştir. Bununla beraber enoksaparinin sekonder osteonekrozun progresyonunu durdurmadığı gözlenmiştir. ${ }^{[15]}$ Steroid kaynaklı femur başı avasküler nekrozlu (FBAVN'li) hayvan modellerinde, enoksaparin, ginkgo biloba özütü (vazodilatör) ve sildenafil ile tedaviden sonra femur başı perfüzyonu artmıştır. Bu sonuçların insan çalışmalarında tekrarlanıp tekrarlanamayacağı ve bu ilaçların sadece koagülopati ile ilişkili FBAVN için endike olup olmayacağı hala net değildir. ${ }^{[16]}$

\section{SONUÇ}

Avasküler nekrozun medikal tedavisinin etkinliği günümüzde hala tartışılmaktadır. Osmani ve ark., Ocak 2001'den Kasım 2015'e kadar PubMed, Embase, CINAHL Plus ve Cochrane veritabanları üzerinden elektronik aramalara dayanan 16 çalışmayı değerlendirmiş ve genel olarak, subkondral çökmeden önce evre I ve II'de invaziv işlemlerden önce hem farmakolojik hem de biyofiziksel tedavi yöntemleri ile yaklaşılabilir görüşüne ulaşmışlardır.[17] Evre III ve ötesinde, bu konservatif tedaviler artık geçerli tedavi seçenekleri değildir. Sonuç olarak günümüzde avasküler nekrozun tedavisinde standart bir medikal tedavi yaklaşımı yoktur. Her hasta etiyoloji ve evresine bağlı olarak ayrı ayrı değerlendirilmelidir. Medikal tedavi uygulanacaksa mutlaka çökme oluşmadan başlanmalıdır.

\section{KAYNAKLAR}

1. Mont MA, Zywiel MG, Marker DR, McGrath MS, Delanois RE. The natural history of untreated asymptomatic osteonecrosis of the femoral head: a systematic literature review. J Bone Joint Surg Am 2010;92(12):2165-70. Crossref

2. Lee YJ, Cui Q, Koo KH. Is There a Role of Pharmacological Treatments in the Prevention or Treatment of Osteonecrosis of the Femoral Head?: A Systematic Review. J Bone Metab 2019;26(1):13-8. Crossref
3. Mont MA, Carbone, JJ, Fairbank AC. Core decompression versus nonoperative management for osteonecrosis of the hip. Clin Orthop Relat Res 1996;324:169-78. Crossref

4. Jager M, Tillmann FP, Thornhill TS, Mahmoudi M, Blondin D, Hetzel GR, Zilkens C, Krauspe R. Rationale for prostaglandin 12 in bone marrow oedema from theory to application. Arthritis Res Ther 2008;10(5):R120. Crossref

5. Meizer R, Radda C, Stolz G, Kotsaris S, Petje G, Krasny C, Wlk M, Mayerhöfer M, Landsiedl F, Aigner N. MRI-controlled analysis of 104 patients with painful bone marrow edema in different joint localizations treated with the prostacyclin analogue ilioprost. Wiener Klinische Wochenschrift 2005;117(7-8):278-86. Crossref

6. Claßen $\mathrm{T}$, Becker A, Landgraeber S, Haversath M, Li X, Zilkens C, Krauspe R, Jäger M. Long-term clinical results after ilioprost treatment for bone marrow edema and avascular necrosis. Orthop Rev 2016;8(1):6150. Crossref

7. Ajmal M, Matas AJ, Kuskowski M, Cheng EY. Does statin usage reduce the risk of corticosteroid-related osteonecrosis in renal transplant population? Orthop Clin North Am 2009;40(2):235-9. Crossref

8. Pritchett JW. Statin therapy decreases the risk of osteonecrosis in patients receiving steroids. Clin Orthop Relat Res 2001:386:173-8. Crossref

9. Cardozo JB, Andrade DMS, Santiago MB. The use of bisphosphonate in the treatment of avascular necrosis: a systematic review. Clin Rheumatol 2008;(27)6:685-8. Crossref

10. Agarwala S, Shah S, Joshi VR. The use of alendronate in the treatment of avascular necrosis of the femoral head: followup to eight years. J Bone Joint Surg Br 2009:91-B(8);1013-8. Crossref

11. Lee YK, Ha YC, Cho YJ, Suh KT, Kim SY, Won YY, Min BW, Yoon TR, Kim HJ, Koo KH. Does Zoledronate Prevent Femoral Head Collapse from Osteonecrosis ? A Prospective, Randomized, Open-Label, Multicenter Study. J Bone Joint Surg Am 2015;97(14):1142-8. Crossref

12. Yuan, HF, Guo CA, Yan ZQ. The use of bisphosphonate in the treatment of osteonecrosis of the femoral head: a meta-analysis of randomized control trials. Osteoporos Int 2016;27(1):295-9. Crossref

13. Li D, Yang Z, Wei Z, Kang P. Efficacy of bisphosphonates in the treatment of femoral head osteonecrosis: A PRISMAcompliant meta-analysis of animal studies and clinical trials. Scientific reports, 2018;8(1):1-11. Crossref

14. Peipei G, Gao F, Wang Y, Zhang Z, Sun W, Jiang B, Wang B, $\mathrm{Li} Z$. The use of anticoagulants for prevention and treatment of osteonecrosis of the femoral head: a systematic review. Medicine 2017;96(16):e6646. Crossref

15. Glueck CJ, Freiberg RA, Wang P. Treatment of osteonecrosis of the hip and knee with enoxaparin. In: Koo KH, Mont M, Jones L, editors. Osteonecrosis. Berlin, Heidelberg: Springer; 2014. p.241-247. Crossref

16. Cao F, Liu G, Wang W, Wang B, Wei X, Lu F, Yang F, Kang K, Wang Y, Yang J, Qin K, Zhao D. Combined treatment with an anticoagulant and a vasodilator prevents steroid-associated osteonecrosis of rabbit femoral heads by improving hypercoagulability. BioMed Res Int 2017. Crossref

17. Osmani F, Thakkar S, Vigdorchik J. The utility of conservative treatment modalities in the management of osteonecrosis: A systematic review. Bull Hosp Jt Dis (2013) 2017;75(3):18692. https://pubmed.ncbi.nlm.nih.gov/28902603/ 